\title{
LINEARIZATION OF ISOMETRIC EMBEDDINGS BETWEEN BANACH SPACES: AN ELEMENTARY APPROACH
}

\author{
GiLles GodeFroy
}

Mathematics subject classification (2010): 46B20.

Keywords and phrases: isometric embeddings, smoothness of norms.

\section{REFERENCES}

[1] Y. Benyamini, J. Lindenstrauss, Geometric Nonlinear Functional Analysis, Vol. 1, Amer. Math. Soc. Colloq. Publ. 48, Amer. Math. Soc., 2000.

[2] T. FigieL, On nonlinear isometric embeddings of normed linear spaces, Bull. Acad. Polon. Sci. Sér. Sci. Math. Astronom. Phys. 16 (1968), 185-188.

[3] G. Godefroy, A glimpse at Nigel Kalton's work, in Banach Spaces and their Applications in Analysis, B. and N. Randrianantoanina Editors, de Gruyter 2007, 1-35.

[4] G. Godefroy, N. J. Kalton, Lipschitz-free Banach spaces, Studia Math. 159, 1 (2003), 121-141.

[5] N. J. Kalton, Spaces of Lipschitz and Hölder functions and their applications, Collect. Math. 55 (2004), 171-217.

[6] N. J. Kalton, The nonlinear geometry of Banach spaces, Rev. Mat. Complut. 21 (2008), 7-60.

[7] N. J. KaLton, The uniform structure of Banach spaces, Math. Annalen, to appear. 